
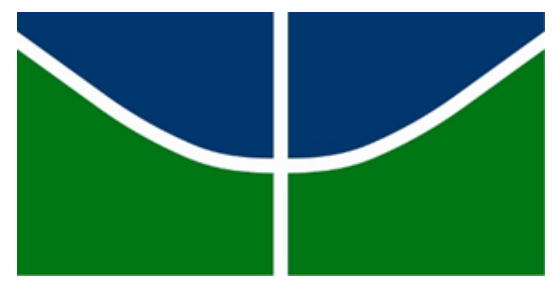

UNIVERSIDADE DE BRASÍLIA

INSTITUTO DE CIÊNCIAS HUMANAS

DEPARTAMENTO DE HISTÓRIA

MARIA ANTONIA OLIVEIRA DURAN MARINS

GUERRA FRIA: A PERSPECTIVA DO BRASIL SOBRE O CONFLITO POLÍTICO ENTRE ESTADOS UNIDOS E CUBA (1959-1961)

ARTIGO

Brasília, Julho de 2017 

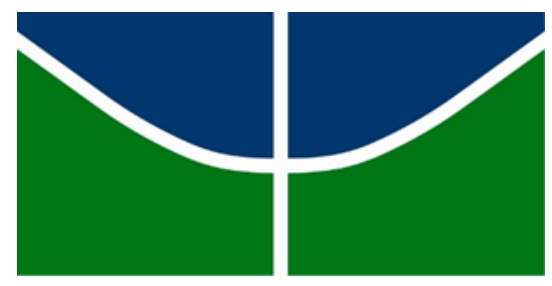

UNIVERSIDADE DE BRASÍLIA

INSTITUTO DE CIÊNCIAS HUMANAS

DEPARTAMENTO DE HISTÓRIA

MARIA ANTONIA OLIVEIRA DURAN MARINS

GUERRA FRIA: A PERSPECTIVA DO BRASIL SOBRE O CONFLITO POLÍTICO ENTRE ESTADOS UNIDOS E CUBA (1959-1961)

Artigo apresentado ao Departamento de História da Universidade de Brasília com o requisito parcial para obtenção do grau de Licenciatura em História.

Orientador: Prof. Dr. Virgílio Caixeta Arraes 


\section{RESUMO}

O presente trabalho tem como principal objetivo analisar o posicionamento do Brasil diante da relação divergente entre os Estados Unidos e Cuba e da construção da nova postura da política externa nacional, que teria uma direção que colocava em primeiro lugar as necessidades do país, em detrimento da relação tradicional com os Estados Unidos. Em meio ao cenário da Guerra Fria, o triunfo da Revolução Cubana foi recebido com tensão em Washington pois este tinha consciência que o movimento carregava consigo um forte sentimento antiamericanismo, o que poderia acarretar choque de interesses na Ilha. Nesse período, o governo brasileiro adota atitudes cautelosas e ponderadas em relação ao problema entre os dois países, pois tinha consciência de que o Brasil tinha a necessidade de uma melhor relação com as outras nações, para assim, contribuir em sua autonomia política e seu desenvolvimento econômico.

PALAVRAS-CHAVE: Cuba. Brasil. Estados Unidos. Política Externa. Revolução Cubana. Guerra Fria. 


\section{Introdução}

O êxito da Revolução Cubana trouxe consigo uma série de divergências com os Estados Unidos, que desde o século XIX, interviram nos assuntos da Ilha. Consolidado o domínio norte-americano sobre a região em 1903 com a instauração da Platt Amendment, ${ }^{1}$ a economia cubana, que permanecia embasada na agricultura, foi vinculada aos Estados Unidos, estabelecendo a dependência da exportação do açúcar para um único mercado. As mudanças impostas pelo novo governo de Cuba atingiram a hegemonia norteamericana no país. “Os interesses tanto econômicos quanto militares dos Estados Unidos dependiam, por conseguinte, da preservação de um status quo que os revolucionários cubanos queriam destruir". ${ }^{2}$ E devido à conjuntura do conflito Leste-Oeste, a política de Washington julgava "inspiração comunista ou influência da União Soviética em qualquer tentativa de reformar estruturas sociais e ainda nas relações econômicas contrárias aos interesses da comunidade norte-americana de homens de negócios", 3 o que agravava as desavenças entre os países.

Revolução, nas palavras de Gianfranco Pasquino, é a tentativa, por meio do uso da violência, "de derrubar as autoridades políticas existentes e de as substituir, a fim de efetuar profundas mudanças nas relações políticas, no ordenamento jurídicoconstitucional e na esfera sócio-econômica", ${ }_{4}$ assim fez o governo cubano. Suas transformações suscitaram o início do confronto entre os anseios da revolução e da política dos Estados Unidos, e o Brasil observava com cautela os embates entre as duas nações. "A tradicional atitude de alinhamento aos Estados Unidos e de busca de uma relação especial com Washington foi abandonada no governo Juscelino Kubitschek" ${ }^{\text {" }}$ que começara a perceber que "para retirar o país do atraso, impunham-se não apenas reformas internas, mas também, mudanças no relacionamento do país com as demais nações", ${ }^{6} \mathrm{o}$

\footnotetext{
${ }^{1}$ Sancionava a tutela econômica e militar dos Estados Unidos e garantia o direito de interferir nos assuntos internos.

${ }^{2}$ MONIZ BANDEIRA, Luiz Alberto. De Martí a Fidel: a Revolução Cubana e a América Latina. $2^{\circ}$ ed. Rio de Janeiro: Civilização Brasileira, 2009, p. 222.

${ }^{3}$ Idem, p. 125.

${ }^{4}$ BOBBIO, Norberto; MATTEUCCI, Nicola; PASQUINO, Gianfranco. Dicionário de política. Vol. 2. Brasília: UnB, 2010

${ }^{5}$ SANTOS, Luís Cláudio Villafañe G. A América do Sul no discurso diplomático brasileiro. Brasília: FUNAG, 2014, p. 96.

${ }^{6}$ BEZERRA, Gustavo Henrique Marques. Brasil-Cuba: relações político-diplomáticas no contexto da Guerra Fria (1959-1986). Brasília: FUNAG, 2010, p. 30.
} 
que o levou a priorizar as necessidades internas e deixar de lado as vontades e pressões do governo norte-americano. Assim, "o Brasil passou a identificar-se claramente com os países em desenvolvimento e trouxe para o discurso diplomático brasileiro, de forma explícita, as questões do debate Norte-Sul". ${ }^{7}$ Com isso:

\begin{abstract}
"A identidade internacional brasileira, com Kubitschek, transitou de uma identidade americana - que buscava diferenciar-se dos vizinhos hispanoamericanos por meio de uma relação especial com os Estados Unidos - para uma identidade claramente latino-americana, em contraposição (mas não necessariamente em conflito) aos Estados Unidos". ${ }^{8}$
\end{abstract}

\title{
A nova "guerra"
}

Diante à grande parte da Europa e Ásia devastada, os Estados Unidos surgem do pós-Segunda Guerra Mundial como potência, ${ }^{9}$ detendo "a maioria do capital de investimento, produção industrial e exportações no mundo, controlando até dois terços do comércio mundial". ${ }^{10}$

Os norte-americanos estavam convictos de que os países envolvidos no conflito, exceto eles, estariam, ao termino, reduzidos a ruinas e a crise econômica, tornando-se possível, o desenvolvimento de seguimentos simpatizantes a revolução social e a políticas econômicas inconciliáveis com o sistema internacional de livre empresa. A certeza foi inteiramente contrariada, pois o ano de 1945 deixou os Estados Unidos ante uma União Soviética notavelmente fortalecida, de doutrina política e econômica incompatível a exercida no país. ${ }^{11}$ As expectativas dos líderes soviéticos também foram frustradas, pois acreditavam que o comunismo necessariamente substituiria o capitalismo, tornando impossível a existência simultânea dos dois sistemas. ${ }^{12}$

\footnotetext{
${ }^{7}$ SANTOS, p. 98.

${ }^{8}$ Idem, p. 97.

${ }^{9}$ Para Martin Wight o poder que constitui uma potência é fundado por alguns elementos como o tamanho da população, posição estratégica e extensão geográfica, recursos econômicos e produção industrial. WIGHT, Martin. A Política do poder. Brasília: UnB, 2002, p. 5.

${ }^{10}$ KARNAL, Leandro. História dos Estados Unidos: das origens ao século XX. São Paulo: Contexto, 2016 , p. 227.

${ }^{11}$ A URSS demostrou que mesmo isolada do mercado mundial após a Revolução de Outubro, foi capaz de criar um desenvolvimento autossuficiente eficaz e imune ao colapso econômico que devastou o sistema capitalista com o crash de Wall Street em 1929.

12 "Os russos vivendo sob uma interpretação totalitária do marxismo, acreditavam que a 'democracia liberal' servia apenas aos interesses de uma burguesia imperialista gananciosa; que uma revolução comunista mundial era inevitável e que a eles cabia auxiliar, militar ou economicamente, movimentos proletários que surgissem. Os americanos, de sua parte, enxergavam no comunismo soviético uma nefasta negação da liberdade e da individualidade, contrária a tudo aquilo por que lutaram desde a fundação de seu país”. TOTA, Antonio Pedro. Os americanos. São Paulo: Contexto, 2013, p. 177.
} 
Nos anos seguintes, as duas nações disputaram a primazia econômica, política e militar mundial, sendo o período conhecido como Guerra Fria, que segundo Eric Hobsbawm, baseava-se em uma:

\footnotetext{
"Crença ocidental, retrospectivamente absurda mas bastante natural após a Segunda Guerra Mundial, de que a Era da Catástrofe não chegara de modo algum ao fim; de que o futuro do capitalismo mundial e da sociedade liberal não estava de modo algum assegurado". ${ }^{13}$
}

Em meio a esse cenário de tensões do sistema bipolar de poder, a divisão do mundo contemporâneo entre as potências por zonas de influência não diminuiu a intensidade do conflito. Ambas receavam a degradação da hegemonia em suas regiões por intermédio de ideais antagônicas que poderiam atravessar as demarcações. No fim dos anos 1940, os reflexos da Guerra Fria atingiram a América Latina, onde as relações de dependência política, econômica e militar da região foram adaptadas de acordo com as necessidades da Guerra e das novas expansões internacionais do capitalismo norteamericano. Como explica Ianni:

"Esse foi o contexto mundial no qual os governantes dos Estados Unidos e da
América Latina adotaram acordos e programas destinados a preservar os países
do hemisfério das influências de origem soviética e das mudanças sociais,
políticas e econômicas que afetassem os interesses das classes dominantes.
Tratava-se de acordos e programas econômicos, políticos, militares e culturais
destinados a intensificar e estender a influência dos Estados Unidos e reduzir
ou controlar a influência de movimentos, partidos, líderes e programas que
tivessem relação direta ou indireta com a resolução socialista ou popular dos
problemas nacionais no hemisfério". 14

\section{Estados Unidos e Cuba antes da Revolução de 1959}

A fim de entender melhor a conturba relação entre os Estados Unidos e Cuba é necessário retroceder alguns anos anterior à data da Revolução Cubana. O forte interesse e intervenção norte-americana, que vem desde o período das guerras de independência da Ilha, desencadeou no século XX constantes desentendimentos entre os dois países.

Ainda sob domínio espanhol, Cuba já despertava interesse dos governantes norte-americanos. Assim como Thomas Jefferson, John Quincy Adams pretendia anexar Cuba, por considera-la a "fronteira natural" dos Estados Unidos e indispensável para a sua segurança no Golfo do México. ${ }^{15}$ No final do século XIX, o país já ultrapassava em desenvolvimento industrial a Inglaterra e Alemanha, com uma economia altamente

\footnotetext{
${ }^{13}$ HOBSBAWM, Eric. Era dos Extremos: o breve século XX: 1914-1991. São Paulo: Companhia das Letras, 1995, p. 228.

${ }^{14}$ IANNI, Octávio. Diplomacia e imperialismo na América Latina. São Paulo: CEBRAP, Caderno 12, 1973, p. 13.

${ }^{15}$ WEINBERG apud MONIZ BANDEIRA, p. 46.
} 
concentrada e de grande potencial de competição no mercado internacional. ${ }^{16}$ Dessa forma, desenvolveu-se um maior interesse pelo controle do acesso a matérias-primas e mercados da região do Caribe. ${ }^{17}$

O processo de independência de Cuba alongou-se durante trinta anos, foi marcado por duas guerras, senda ela a última colônia da América Latina a libertar-se da Espanha em 1898. O primeiro levante, a chamada Guerra dos Dez Anos, iniciou-se no dia 10 de outubro de 1868, terminando em 1878 não cumprindo as expectativas. No dia 11 de abril de 1895, uma expedição desembarcou na Ilha mobilizando vários setores populares. ${ }^{18}$ Quando a vitória dos independentista estava próxima a ser concretizada, os Estados Unidos intervieram no combate em 1898, declarando guerra à Espanha, depois que um encouraçado seu foi bombardeado, supostamente, por tropas espanholas no porto de Havana, matando 260 marinheiros. ${ }^{19}$

Logo ao ser derrotada, a Espanha assinou um armistício com os Estados Unidos em Washington e um tratado de paz em Paris, no qual reconhecia a independência de Cuba. O país passou a ser ocupado por tropas norte-americanas, onde se estabeleceu um governo provisório tendo à frente o general John R. Brooke que permaneceu no poder até a posse do primeiro presidente eleito, Tomás Estrada Palma, em 1902. O domínio dos Estados Unidos sobre a região consolidou-se com a instauração da Platt Amendment, a qual sancionava a tutela econômica e militar dos Estados Unidos e garantia o direito de interferir nos assuntos internos. Assim, a economia cubana, que permanecia embasada na agricultura, foi vinculada aos Estados Unidos, estabelecendo a dependência da exportação do açúcar para um único mercado.

\footnotetext{
${ }^{16}$ AYERBE, Luis Fernando. A Revolução Cubana. São Paulo: Editora Unesp, 2004, p. 22.

${ }^{17}$ Além do açúcar, minério de ferro, manganês, tabaco e ferrovias, os interesses norte-americanos também se mostravam na estrutura da propriedade cubana, ansiando o controle de terras, centrais açucareiras e engenhos.

18 A ação foi comandada por Máximo Gómez, na qual também participava José Martí, grande ideólogo do movimento de independência e fundador do Partido Revolucionário Cubano.

${ }^{19}$ Sobre o afundamento do navio de guerra Maine há divergências sobre a causa. Luiz Fernando Ayerbe cita que a explosão aconteceu em decorrência de uma mina submarina, mas devido à profundidade da lama nas aguas do porto, não foi possível fazer uma investigação. Mesmo sem comprovação, o governo dos Estados Unidos adotou a hipótese de que o naufrágio foi um ato de sabotagem dos espanhóis, o que levou o país a declarar guerra aos colonos. Já Emir Sader, afirma que o ocorrido foi forjado pelos norteamericanos para possibilitar sua entrada militar na guerra, fato revelado posteriormente.
} 


\section{Ameaça Vermelha?}

Em 10 de março de 1952, Cuba foi surpreendida com o golpe militar realizado por Fulgencio Batista, coronel da reserva e ex-presidente da república entre 1940 e 1944, a ser reconhecido sem dificuldades pelos Estados Unidos. ${ }^{20} \mathrm{~A}$ ação interrompeu "o caminho da política institucional para inúmeras lideranças que apostavam na legitimidade do sistema como premissa para o encaminhamento das mudanças socioeconômicas de que o país necessitava". ${ }^{21}$ Pela segunda vez no poder, Batista deu continuidade aos vícios do primeiro mandato, sendo seu governo marcado por forte repressão, alta inflação, corrosão salarial e várias acusações de corrupção pela oposição.

Em meio a formação de grupos de resistência contra o governo ilegítimo, os quais utilizaram as universidades como palco para as manifestações, destacou-se a figura de Fidel Castro. ${ }^{22}$ O jovem advogado membro do Partido Ortodoxo ${ }^{23}$ foi candidato a deputado nas eleições de $1^{\circ}$ de junho, anuladas pelo golpe de Estado. Assim, recorreu a um tribunal de Havana com provas de que a ação do governante transgredia várias leis do país. Sem o apoio do judiciário para solucionar o caso, Castro, frustrado e decepcionado com a realidade do país, e convicto de que a democracia retornaria com a derrubada do regime Batista, reuniu militantes para executar a primeira ação revolucionária: o assalto aos quartéis de Moncada e Bayamo. ${ }^{24}$

Marcada para o dia 26 de julho de 1953, a operação não teve sucesso. O aparecimento inesperado da patrulha do Exército iniciou um ataque antes do previsto, deixando inúmeras baixas. Os principais líderes, incluindo, Castro e seu irmão, Raul, foram presos. Sentenciado a quinze anos de prisão, Fidel Castro escreveu sua defesa, intitulando-a A história me absolverá, a qual narrava os objetivos da revolução e o programa de transformações sociais, econômicas e políticas que o novo governo

\footnotetext{
${ }^{20}$ Pela primeira vez no poder, o nome de Fulgencio Batista veio associado à luta contra a ditadura de Machado, que governou o país entre 1925 e 1933. Já pela segunda vez à frente do governo cubano, Batista aparece com um movimento político muito diferente do anterior.

${ }^{21}$ AYERBE, p. 26

${ }^{22}$ Filho de um bem sucedido fazendeiro espanhol, Fidel Castro ingressou na faculdade de Direito da Universidade de Havana em 1945. Desde cedo, envolveu-se em assuntos políticos, participando de um movimento para derrubar o ditador Trujillo, da República Dominicana em 1947, o que acabou não se concretizando.

${ }^{23}$ Eduardo Chibás fundou o Partido Cubano (Ortodoxo) em 15 de maio de 1947 com "um programa político de combate à degradação econômica e moral a que se haviam entregue todos os governos da pseudo-república”. SADER, Emir. A Revolução Cubana. São Paulo: Editora Moderna, 1985, p. 15.

24 "A escolha se deveu a que a região oriental do país tinha se caracterizado como a mais radical politicamente já desde as lutas de independência do século XIX e que, portanto, mais facilmente poderia dar apoio ao movimento revolucionário". Idem, p. 19.
} 
assumiria, onde "previam-se ações direcionadas a melhorar as condições de vida do povo (aumentos salariais, direitos trabalhistas, diminuição de aluguéis residenciais etc.) ou diversificar o perfil econômico do país, fortalecendo a industrialização". ${ }^{25}$

Depois de receber liberdade por anistia, em 15 de maio de 1955, Castro seguiu para o México, onde se dedicou a planejar uma nova ofensiva articulando juntamente com o Movimento 26 de Julho ${ }^{26}$ que permanecia em Cuba. Nesse período, recebeu militantes para participar da força expedicionária. Partiram para Cuba na madrugada do dia 25 de novembro de 1956, a bordo do barco Granma:

"No plano de ação a ser desenvolvido em terras cubanas, caberia ao M-26/7
promover um levantamento popular em Santiago no dia 30 de novembro, data
prevista para o desembarque do Granma. Embora sem atingir a força esperada,
as ações em terra seguem o cronograma, o que não acontece com o grupo
expedicionário, que só consegue desembarcar três dias depois, na Praia dos
Colorados, Enseada de Turquino no momento em que as forças de Batista
estavam de sobreaviso, desfechando um ataque devastador no dia 5 de
dezembro". ${ }^{27}$

As árduas retaliações cometidas pelo Exército de Batista, não foram suficientes para extinguir a insurreição que ganhava força ao se propagar para as demais regiões, dando início à ação guerrilheira no campo em Sierra Maestra. Ao notar que não havia meios para reverter tais circunstâncias, no réveillon de 1959, Batista renunciou e fugiu para República Dominicana. Outros dirigentes da administração cubana propuseram acordos com o grupo, mas não tiveram êxito. No dia 8 de janeiro de 1959, Fidel Castro e sua tropa entraram em Havana saudados como heróis pela população. Washington recebeu a notícia sobre a vitória dos rebeldes com grande nervosismo, visto que ter um governo composto por integrantes de um movimento, o qual demonstrava um notável sentimento antiamericanismo, ${ }^{28}$ significava futuros problemas para a presença dos Estados Unidos na Ilha.

O novo regime adotou um programa governamental semelhante ao documento: A história me absolverá. A assinatura da Lei de Reforma Agrária, no dia 17 de maio do mesmo ano, foi a medida mais radical empregada; dela criou-se o Instituto Nacional de

\footnotetext{
${ }^{25}$ AYERBE, p. 61.

${ }^{26}$ M-26 ou M-26/7, o nome refere-se a data do assalto ao Moncada. O grupo de resistência permaneceu em Cuba durante o período em que Castro esteve em Cuba, auxiliando-o na organização para a nova luta armada.

${ }^{27}$ AYERBE, p. 35

${ }^{28}$ A sufocante intervenção da economia norte-americana nos países da América Latina, principalmente nos da América Central e Caribe, os quais apontavam seu imperialismo como mentor dos problemas sociais e de desenvolvimento, provocou o aparecimento de segmentos ideológicos contrários aos Estados Unidos.
} 
Reforma Agrária, encarregado de operar na economia rural e estabelecer as áreas de propriedade pública e privada, o que gerou reações negativas por parte dos Estados Unidos, pois essa primeira reforma atingiu diretamente as empresas norte-americanas em Cuba, entre elas a United Fruit Sugar Company, Guantánamo Sugar Company e várias outras. Devido à lógica da Guerra Fria, Washington considerava qualquer reforma, tanto social quanto econômica, que fosse oposta aos interesses norte-americanos, como atuação comunista ou de influência soviética.

"Embora radicais, nem Fidel Castro, nem qualquer de seus camaradas eram comunistas, nem (com duas exceções) jamais disseram ter simpatias marxistas de qualquer tipo", ${ }^{29}$ assim como o Partido Comunista de cubano não expressava simpatia por Castro, sendo uma relação frígida. Dessa forma o M-26-7 pode ser considerado de "tendência populista ou social-democrata, continuador da ortodoxia de Eduardo Chibás". ${ }^{30}$ Após debaterem se o movimento era ou não comunista, os Estados Unidos chegaram à conclusão de que não, como foi declarado pelo encarregado de Imprensa do Departamento de Estados, Lincoln White, em uma coletiva após o triunfo da Revolução, quando questionado se dentro do governo dos rebeldes havia muitos comunistas, respondeu: "não, pois os rebeldes sempre evitaram a infiltração vermelha em suas fileiras". ${ }^{31}$ Nesse momento, a preocupação dos Estados Unidos não era a natureza ideológica do novo governo e sim, suas transformações, principalmente a reforma agrária, que atingiu as empresas norte-americanas proprietárias de grandes latifúndios.

\section{A América Latina}

Como já mencionado, as relações de dependência da América Latina, décadas pós Segunda Guerra Mundial, foram estabelecidas conforme as exigências da Guerra Fria e as conveniências dos Estados Unidos que se julgavam "guardiões" do mundo livre em combate a expansão soviética, realizando assim, crescentes intervenções na política interna dos países da região. Segundo Moniz Bandeira:

“A preocupação dos Estados Unidos na América Latina não era propriamente defender a ordem democrática e as liberdades políticas, e sim assegurar um

\footnotetext{
${ }^{29}$ HOBSBAWM, p. 427.

${ }^{30}$ MONIZ BANDEIRA, p. 202.

${ }^{31}$ Vencida em luta desesperada em Havana a gente de Batista. O Globo. Rio de Janeiro, p. 10, 03 jan. 1959. Disponível em: http://acervo.oglobo.globo.com/busca/?tipoConteudo=pagina\&ordenacaoData=relevancia\&allwords=Rev olu\%C3\%A7\%C3\%A3o+Cubana\&anyword=\&noword=\&exactword=\&decadaSelecionada=1950\&anoSe lecionado=1959\&mesSelecionado=1\&diaSelecionado=3. Acesso em: 7 mai. 2017.
} 
clima favorável aos seus negócios e investimentos privados, bem como acesso às fontes de matérias-primas, sobretudo petróleo". ${ }^{32}$

Os Estados Unidos não tratavam a América Latina com prioridade até a Revolução Cubana. "Esse fenômeno caracterizava-se pela ausência de investimentos públicos norte-americanos para a infraestrutura e de bens de capital". ${ }^{33}$ A progressiva insatisfação com o descaso norte-americano em relação as nações latino-americanas, transformaram-se em maciça pressão política e econômica para modificar as relações de dependência e assim, alcançar o desenvolvimento nacional. Além dos ressentimentos devido a quantidade de fundos que eram destinados para a América Latina, a sufocante prevalência econômica norte-americana sobre esses países desencadeou conflitos sociais internos que começaram a assumir conotações ideológicas.

A Revolução ocorreu no final do mandato do presidente Dwight D. Eisenhower (1953-1961), cujo governo caracterizou-se pelo endurecimento da Guerra Fria e por promover a "desestabilização de governos cuja trajetória indica um possível aumento da influência soviética". ${ }^{34}$ A insatisfação dos latino-americanos com os Estados Unidos e seus dirigentes ficou bastante clara por meio das demonstrações de violência contra o vice-presidente Richard Nixon em maio de 1958, quando realizou visitas a alguns países da América latina, a começar pela Argentina, Uruguai, Equador, Colômbia, Peru e Venezuela. Por onde passava, Nixon foi recebi com grande agressividade popular; a manifestação mais intensa ocorreu na Venezuela que chegou a assumir caráter de motim. Em meio a este cenário fica claro que a Guerra Fria somada à Revolução Cubana foi responsável por construir dois segmentos na América Latina: o combate ao comunismo e a luta contra o imperialismo norte-americano.

\section{Relações interamericanas}

Durante esse período, a América estava entrelaçada por dois acordos que definiram as relações interamericanas e que deveriam ser levados em consideração: o Tratado Interamericano de Assistência Recíproca (TIAR) ou o Tratado do Rio de Janeiro, e a Organização dos Estados Americanos (OEA).

\footnotetext{
${ }^{32}$ MONIZ BANDEIRA, p. 125

${ }^{33}$ VIZENTINI, Paulo G. Fagundes. Da barganha nacionalista à política externa independente, 1951-1964; relações internacionais e desenvolvimento no Brasil. In: CERVO, Amado Luiz. DÖPCKE, Wolfgang (org.). Relações Internacionais dos Países Americanos. Brasília: Linha Gráfica Editora, 1994, p. 325.

${ }^{34}$ AYERBE, p. 45.
} 
Assinado em 2 de setembro de 1947, o Tratado do Rio de Janeiro estabelecia um sistema de defesa hemisférica, com base no Pan-americanismo, que prescrevia em seu artigo $3^{\circ}$, que "uma agressão qualquer país americano seria considerada como um ato de hostilidade a todos os países do continente". ${ }^{35}$ Além disso, o Tratado também procurava delinear as ações de solidariedade continental indicadas em outras reuniões interamericanas, especialmente na Conferência de Chapultepec. ${ }^{36}$ Fruto da IX Conferência Interamericana, pela Carta de Bogotá, a OEA foi criada em 30 de abril de 1948, seu nascimento ocorre no mesmo momento em que há um pequeno declínio da política da boa vizinhança lançada pelo presidente norte americano Roosevelt: ${ }^{37}$

"Daí em diante, a solidariedade continental, entendida como corolário de uma política de conciliação dos mútuos interesses dos países latino-americanos e dos EUA, esquecendo-se que aqueles eram apenas 'o quintal dos EUA', entra em agonia pela exacerbação da divisão ideológica do mundo. O problema central reside no fato de que os EUA colocam como eixo principal de suas relações coma América Latina a defesa contra a infiltração comunista, o que resulta numa política de contemporização, quando não de incentivo direto às ditaduras mais reacionárias". 38

Os desdobramentos dos revolucionários em Cuba levam os Estados Unidos a procurarem apoio dos países americanos por meio dessas duas alianças para realizar intervenções e sanções a Ilha.

\section{O Brasil em meio ao conflito}

\section{O desempenho da diplomacia brasileira}

Enquanto a vitória dos guerrilheiros causava alvoroço dentro e fora de Cuba, o Brasil vivia o penúltimo ano da presidência de Juscelino Kubitschek, o qual traçou como meta de seu governo vencer o subdesenvolvimento através do projeto nacional-desenvolvimentista, ${ }^{39}$ tornando-o também, ponto central das relações

\footnotetext{
${ }^{35}$ BEZERRA, p. 28.

${ }^{36}$ A ata da Conferência de Chapultepec, realizada na cidade do México, entre 21 de fevereiro a 8 de março de 1945, pode ser considerada o documento mais importante para a construção do sistema interamericano no pós-Segunda Guerra Mundial. Tendo como objetivos da reunião propor a criação de um sistema de defesa interamericano, coordenar o sistema interamericano com os organismos internacionais, particularmente a ONU e criar um programa de ajuda econômica para o desenvolvimento da América Latina no pós-guerra.

${ }^{37}$ No início de seu governo, Franklin Delano Roosevelt, já havia declarado que respeitaria a autonomia dos vizinhos do Sul. Substituiu a política do Big Stick pela Política da Boa Vizinhança (Good Neighbor Policy) Os princípios dessa política eram reafirmados nas Conferência Pan-Americana pelos funcionários do Departamento de Estado. TOTA, p. 160.

${ }^{38}$ ODÁLIA, Nilo. O Brasil nas relações internacionais: 1945-1964. In: MOTA, Carlos Guilherme (org.). Brasil em perspectiva. Rio de Janeiro: Bertrand Brasil, 1995, p. 359-360.

39 A proposta econômica de Juscelino Kubitschek envolvia investimento público e incentivo para o investimento privado. Focava na industrialização e na construção de infraestrutura precisa para sustentá-la.
} 
internacionais do Brasil, ao entender que para tirar o país do atraso seria necessário mudar suas relações com demais países. Notando a efervescência do antiamericanismo nos países da América Latina e depois dos ataques sofridos por Nixon em sua viagem mal sucedida, JK deu início à troca de cartas pessoais com Eisenhower, nas quais propôs a Operação Pan-Americana (OPA) em 1958: ${ }^{40}$

\begin{abstract}
"Esta era uma proposta de cooperação internacional de âmbito hemisférico, na qual se insistia na tese de que o desenvolvimento e o fim da miséria seriam as maneiras mais eficazes de se evitar a penetração de ideologia exóticas e antidemocráticas, que se apresentavam como soluções para os países atrasados". ${ }^{41}$
\end{abstract}

As transformações do governo cubano suscitaram o início do confronto entre os interesses da revolução e da política dos Estados Unidos. Em fevereiro de 1960, Eisenhower visitou o Brasil e em meio a ocasião JK "ofereceu-se como a mediador no conflito entre os dois países, recusando-se a aceitar qualquer tipo de solução que considerasse a intervenção a Cuba". ${ }^{42}$ Após o reestabelecimento das relações diplomáticas com Moscou em 1960, rompidas por Batista em 1952, Cuba firmou um acordo de comércio ${ }^{43}$ com a União Soviética e aceitou seu apoio militar. ${ }^{44} \mathrm{Com}$ isso, o presidente norte-americano resolveu não tolerar o governo Castro por mais tempo, muito menos aceitar que a URSS estabelecesse um ponto de apoio na América Latina.

\footnotetext{
${ }^{40}$ Em meio aos desdobramentos das negociações, ficou claro para o governo brasileiro que os Estados Unidos não tinham a menor preocupação com subdesenvolvimento de qualquer região, a não ser que houvesse um verdadeiro perigo comunista nela. Como afirmam Amado Cervo e Clodoaldo Bueno, a OPA não alcançou o resultado esperado, pois "careceram-lhe projetos específicos para se passar à ação" como afirmam Cervo e Bueno. CERVO, Amado Luiz. História da política exterior do Brasil. Brasília: UnB, 2015, p. 316.

${ }^{41}$ CERVO \& BUENO, p. 311.

${ }^{42}$ QUINTANEIRO, Tania. Cuba e Brasil: da revolução ao golpe (1959-1964). Belo Horizonte: UFMG, 1988 , p. 27.

${ }^{43}$ Firmado no dia 13 de fevereiro de 1960, "o acordo de comércio mediante o qual a União Soviética, além de outorgar a Cuba um crédito de US\$ 100 milhões para a aquisição de produtos soviéticos, comprometiase a comprar 425.000 toneladas de açúcar, no curso de 1960, e cinco milhões de toneladas, no próximo quinquênio, ao preço de 2,78 cents por libra, ligeiramente abaixo da cotação no mercado mundial. Pagaria $20 \%$ em divisas e o resto com produtos, entre os quais petróleo". SMITH, BONSAL apud MONIZ BANDEIRA, p. 238.

${ }^{44}$ Os Estados Unidos e a União Soviética protagonizaram momentos de tensão na Crise de Suez. A nacionalização da companhia franco-britânica que administrava o Canal de Suez pelo governo egípcio, em julho de 1956, faz com que a França e a Inglaterra, formasse uma coalização para um ataque militar ao país, na qual Israel também participou, utilizando a situação para apresentar o presidente do Egito, Gamal Abdel Nasser, como agressor devido suas ações no conflito árabe-israelense. Iniciada em 23 de outubro de 1956, a Guerra de Suez foi duramente criticada pelos Estados Unidos, pois a situação poderia deflagrar um confronto direto com a União Soviética, já que o Egito contava com o apoio oriental. No desfecho da Guerra, a União Soviética saiu com prestigio elevado, por derrotar os países colonialistas alinhados aos Estados Unidos.
} 
Com intuito de gerar descontentamento interno, as empresas norte-americanas foram orientadas pelo secretário do Tesouro, Robert Anderson, que não refinassem petróleo soviético, o que levou à intervenção nas instalações das refinarias por parte do governo revolucionário, entre os dias 29 de junho e $1^{\circ}$ de julho. Em resposta, Eisenhower determinou o corte de 700.000 toneladas da cota de açúcar no valor de US\$ 90 milhões, que indicou, praticamente, a suspensão da exportação da mercadoria para os Estados Unidos. Aproveitando o momento, o líder soviético, Nikita Kruschev, anunciou que compraria o açúcar cubano e ofereceu seu poderio nuclear ao governo cubano contra qualquer intervenção armada por parte dos norte-americanos.

Solicitada em caráter de urgência pelo Peru, a VII Reunião de Consulta da OEA, realizada em San José da Costa Rica de 22 a 29 de agosto de 1960, tinha como pauta principal discutir a situação do Caribe e a intervenção de uma potência extracontinental em assuntos americanos. Para a ocasião, Kubitschek aconselhou o chanceler Horácio Lafer a que agisse com cautela referente ao assunto cubano e que relembrasse a carta enviada a Eisenhower, alertando que acontecimentos políticos como o de Cuba poderiam surgir em outros países devido à ausência de afirmativas construtivas na América.

As instruções feitas a Lafer foram no intuito de que o Brasil não deveria assumir uma posição tendente a condenar Cuba, bem como expressar compreensão a suas objeções e soberania, mas entendia que uma aliança com Moscou não seria a escolha mais adequada. O Brasil e os Estados Unidos tinham interesse em comum de que Cuba não caísse em órbita soviética e assim, preservariam a ordem interamericana, mas ambos divergiam com relação aos meios para chegar a tal finalidade. Kubitschek acreditava que o diálogo franco e firme, usando uma linguagem amiga, com as duas nações seria um caminho para ajustar as desavenças, enquanto Washington pretendia ir pelo uso da força através do poderio militar ${ }^{45}$ que de acordo com o presidente brasileiro apenas jogaria Cuba nos "braços" soviéticos.

\footnotetext{
${ }^{45} \mathrm{O}$ governo Eisenhower patrocinou atos de sabotagem em Cuba como repreensão ao novo governo, mas o plano de realizar uma invasão a Ilha foi apenas colocado em prática pelo seu sucessor John Kennedy. Em 17 de abril de 1961, um dia após Fidel Castro declarar o caráter socialista da Revolução Cubana, ocorreu a invasão à Baía dos Porcos por contra revolucionários apoiados pelos Estados Unidos. A fracassada ação gerou severas críticas aos norte-americanos. Como foi noticiado pela imprensa brasileira, após agressão a Cuba, um grupo de deputados de vários partidos foram para o Rio de Janeiro com o objetivo de coordenar um movimento nacional em defesa do princípio de autodeterminação. A organização tinha como base a tese de que "o esmagamento da revolução cubana, por meio da força militar empregada de fora, teria repercussões negativas no processo de evolução pacifica de ideias e fatos que interessam ao desenvolvimento brasileiro, assim como esses fatos e ideias receberam estimulo considerável no Continente
} 
Na reunião, o discurso dos Estados Unidos em oposição a Cuba, acusando-a de vínculo com os comunistas, não impressionou aos delegados que continuaram a entender a questão cubana como um conflito bilateral com os norte-americanos. Durante a ocasião, o representante do Brasil, Horácio Lafer, sugeriu um "Protocolo Adicional de Assistência Econômica ao TIAR" que visaria a "fortalecer a solidariedade continental e o sistema interamericano ante as ameaças de intervenção que possam afetá-los" 46 e insistiu no debate sobre as causas da inquietação dos países latino-americanos e suas consequências, que poderiam colocar em perigo a democracia e o sistema interamericano. Como afirma Tânia Quintaneiro, nessa etapa, "a posição do Brasil em relação ao conflito Cuba-EUA era, conforme a sua tradição conciliatória"; a ênfase recaía "nas teses e nos princípios que motivaram a OPA". ${ }^{47}$

Mais uma vez, o discurso brasileiro salientou que o maior problema dos países da América Latina era o subdesenvolvimento que poderia levar outras nações a seguirem os mesmos passos de Cuba, visto que a Revolução era vista com simpatia por essas populações, tornando-se inspiração para solucionar os problemas econômicos e sociais existentes. A Declaração de San José da Costa Rica, ata da Reunião, foi elaborar com oito resoluções, das quais a primeira condena "energeticamente a intervenção ou ameaça de intervenção, mesmo condicional, de uma potência extracontinental em assuntos das Repúblicas americanas"; ${ }^{48}$ caso houvesse a concessão de uma interferência extracontinental, por algum membro da OEA, colocaria em "perigo a solidariedade e a segurança da região, o que obriga a esse organismo a desaprová-la e repeli-la com igual energia". ${ }^{49}$ Foram aprovadas também mais dez resoluções, incluindo a responsabilidade do Conselho da OEA em preparar com os governos americanos o Protocolo Adicional proposto pelo Brasil.

com a vitória dos revolucionários sobre o regime de Batista". Os parlamentares entregaram uma mensagem dirigida a John Kennedy como um apelo para que "o Governo norte-americano continue a justificar sua liderança no mundo ocidental e não intervenha em Cuba, assegurando ao povo cubano o direito de autodeterminação defendido pelo Presidente do Brasil com apoio na opinião pública”. Deputados lançam movimento nacional em defesa do princípio de autodeterminação. Jornal do Brasil. Rio de Janeiro, p. 3. 19 abr. 1961.
Disponível
em: http://memoria.bn.br/DocReader/DocReader.aspx?bib=030015_08\&PagFis=17297\&Pesq=Invas\%c3\%a3 o a Cuba. Acesso em: 6 jul. 2017.

${ }^{46}$ QUINTANEIRO, p. 28.

${ }^{47}$ Idem.

${ }^{48}$ Ibidem, p. 29

${ }^{49}$ Ibidem. 
Reações a resolução da conferência

A ata final da VII Reunião de Consulta da OEA não satisfez as expectativas da gestão Eisenhower, nem agradou a Fidel Castro. A atuação dos Estados Unidos contra Cuba na questão do petróleo e o corte da cota de açúcar desvigorou sua posição. Além de não conseguir apoio para realizar uma sanção a Cuba, na Reunião, o secretário de Estado norte-americano, Christian Herter, tolerou um parágrafo do documento que reafirmava o "princípio de não intervenção de um Estado americano nos assuntos internos ou externos dos demais Estados americanos" $" 50$ e reiterando que:

"Cada Estados tem o direito de desenvolver livre e espontaneamente sua vida
cultural, política e econômica, respeitando os direitos da pessoa humana e os
princípios da moral universal e, por conseguinte, que nenhum Estado
americano pode intervir com o propósito de impor a outro Estado americano
suas ideologias ou princípios políticos, econômicos e sociais". 51

Kubitschek foi informado por Lafer que todos os esforços foram feitos para que a soberania e autodeterminação de Cuba fossem respeitadas e que a ela cabia acreditar "seu destino político à indissolúvel solidariedade pan-americana, avessa às investidas do comunismo internacional". ${ }^{52}$ Porém Castro não era inocente em confiar no amparo pan-americano, depois do que aconteceu com Arbenz na Guatemala, ${ }^{53}$ e muito menos de que os Estados Unidos respeitaram o preceito da não intervenção nos assuntos de outro Estado americano. Insatisfeito com o resultado da Reunião, o líder cubano, perante a uma multidão declarou que tanto a União Soviética como a China estavam aproveitando da conjuntura de um Estado americano para fraturar a unidade continental, colocando assim, em risco a paz e a segurança da América. E ressaltou que o culpado pela revolução estar acontecendo em Cuba era do imperialismo norte-americano. Na mesma ocasião, aprovou a Declaração de Havana, na qual agradecia o apoio militar da União Soviética em caso

\footnotetext{
${ }^{50}$ MONIZ BANDEIRA, p. 267.

51 Reunião de Consulta dos Chanceleres Americano, VII, 1960, San José da Costa Rica. Ata Final. Disponível em: http://www.oas.org/council/sp/RC/RCactas.asp. Acesso em: $1^{\circ}$ jun. 2017

${ }^{52}$ MONIZ BANDEIRA, p. 267.

${ }^{53}$ Em 17 de junho de 1952, o Decreto $\mathrm{n}^{\circ}$ 900, imposto pelo governo da Guatemala deflagrou a reforma agrária, a qual previa a expropriação e divisão de terras não cultivadas. A ação atingiu a United Fruit Company, maior empresa norte-americana no país, o que não agradou o presidente Harry Truman. No ano seguinte, os problemas com o país recrudesceram, levando Eisenhower a autorizar a preparação de uma invasão camuflada na Guatemala com intuito de derrubar o governo Arbenz, a chamada Operation PBSUCESS. Envolvidos pela paranoia anticomunista e com receio de uma possível aproximação da Guatemala com Bloco Soviético, fez com os Estados unidos colocassem a operação em prática. Em 18 de junho de 1954, o chefe do movimento, Carlos Castillo Armas, entrou no país com um pequeno exército de mercenários. Depois do bombardeio na capital da Guatemala, Arbenz, renunciou. No dia 29, após uma negociação, o poder foi entregue a Armas, homem de confiança da CIA.
} 
de invasão dos Estados Unidos e mostrava-se disposto a ir até as últimas consequências para combater o país.

Antes mesmo da reunião, Castro, após Eisenhower instigar as empresas a desertar as atividades na Ilha, deu início à nacionalização de todas as propriedades norte-americanas: usinas de açúcar, companhias de telefone e energia elétrica, e demais setores industriais. Com efeito, a radicalização do governo cubano colaborou para o seu fortalecimento materialmente e ao mesmo tempo interrompeu a presença dos Estados Unidos no país, arruinando seus suportes internos do sistema capitalista, o que gerou severas críticas à administração Eisenhower, acusando-o de permitir instalação comunista no Hemisfério. No entanto, de forma parcialmente acobertada, a CIA, há um tempo, treinava e patrocinava forças paramilitarares na Guatemala, a qual articulava com a atuação contra revolucionária em solo cubano, especificamente na Serra de Escambray e Sierra Maestra, com intuito de fazer um ataque à Ilha.

Os Estados Unidos não queriam declarar abertamente um confronto armado contra Cuba, pois isso afetaria sua imagem, levando em conta a grande popularidade da Revolução Cubana na América Latina, então investiu em sabotagens e pequenas invasões por efetivo bem reduzido de homens, as quais não deram certo, e o governo cubano tinha conhecimento desses atos, mas não conseguiu provar o envolvimento norte-americano. Ao comemorar, em 2 de janeiro de 1961, o segundo aniversário da Revolução Cubana, Fidel Castro "acusou a embaixada dos Estados Unidos em Havana de construir um centro de subversão e espionagem e exigiu a redução de seus funcionários, da ordem de algumas dezenas, para 11 funcionários equivalente ao que a Cuba mantinha em Washington". ${ }^{54}$ Eisenhower seguiu a proposta de Daniel Braddock, encarregado de Negócios norteamericanos, de romper relações diplomáticas com Cuba, já que não havia cidadãos norteamericanos e interesses para proteger na Ilha e por considerar sua continuidade inconciliável com as pressões internas e externas essenciais para a derrubada do governo rebelde. Desse modo, no dia 3 de janeiro de 1961, os Estados Unidos e Cuba romperam suas relações.

\section{Conclusão}

Acima do conflito de ideologia presente no contexto, o fator econômico foi a chave para a tomada de decisão de cada país supracitado. Cuba, envolvida pelo

\footnotetext{
${ }^{54}$ MONIZ BANDEIRA, p. 288.
} 
sentimento nacionalista, buscou na Revolução livrar-se do imperialismo norte-americano, que a reduziu a um sistema de monocultura de exportação, e assim, pode realizar transformações internas voltadas para o desenvolvimento econômico e social. Sua aproximação com a União Soviética não significava o compartilhamento de doutrina política, apesar de Fidel ter declarado mais tarde, em abril de 1961, o caráter socialista da Revolução e depois ter anunciado sua adesão ao marxista-leninista. Em meio a essas atitudes, o líder cubano buscou salvar a Revolução, já que seus desdobramentos levaram a graves sanções econômicas por parte dos Estados Unidos, rompendo relação com o maior comprador de seu produto, o açúcar, pois as exportações para outros países do Hemisfério não eram significativas; entretanto ao receber a proposta de vendê-lo à União Soviética tornou-se um caminho para alcançar o progresso a que tanto almejava.

A apreensão de Washington com o governo revolucionário girava em torno das mudanças que eram empregadas, as quais atingiram diretamente os interesses e lucros das grandes empresas norte-americanas que haviam investido centenas de milhares de dólares na Ilha. O temor da infiltração comunista em sua zona de influência também estava associado ao âmbito econômico visto que poderia quebrar a hegemonia dos Estados Unidos na região e afetaria seu mercado capitalista. A diplomacia no período Kubistchek pode ser dividida em duas etapas, nos primeiros anos, a política externa brasileira deu continuidade ao tradicional alinhamento automático com os Estados Unidos, no ano de 1958, o quadro começa a mudar, momento em que o governo retoma a barganha nacionalista semelhante ao período Vargas, dando início a uma conscientização voltada para os problemas específicos do país.

Tendo como meta superar o subdesenvolvimento nacional, reformas internas não seriam suficientes para alcançar tal finalidade, mudanças no relacionamento com as demais nações, independente de seus segmentos ideológicos, visando expandir mercados para os produtos brasileiros também seriam necessárias. Portanto, criou-se um vínculo entre a política externa e o desenvolvimento. Nota-se que a diplomacia brasileira estende seu campo de manobra através do "deslocamento do seu centro de decisões do plano exterior para o interno". ${ }^{55}$ O começo da nova fase da política externa brasileira, inaugurada por Juscelino Kubistchek, seria concretizada na gestão de Jânio Quadros com a chamada Política Externa Independente e impulsionada pelo governo João Goulart.

${ }^{55}$ ODÁLIA, p. 350. 


\section{Referências Bibliográficas}

\section{Fontes primárias}

\section{Documentos}

Reunião de Consulta dos Chanceleres Americano, VII, 1960, San José da Costa Rica. Ata Final. Disponível em: http://www.oas.org/council/sp/RC/RCactas.asp.

Jornais

Correio da Manhã. Disponível em: http://bndigital.bn.gov.br/hemeroteca-digital/.

Jornal do Brasil. Disponível em: http://bndigital.bn.gov.br/hemeroteca-digital/.

O Globo. Disponível em: https://oglobo.globo.com/.

\section{Fontes secundárias}

ARRAES, Virgílio; DURAN, Maria Antônia. A Revolução Cubana Revistada: poder, transgressão e resistência. In: XAVIER, Lídia de Oliveira. AVILA, Carlos F. Domínguez (org.). Política, Cultura e Sociedade na América Latina: estudos interdisciplinares e comparativos. Curitiba: CRV, 2016.

AYERBE, Luis Fernando. A Revolução Cubana. São Paulo: Unesp, 2004.

Luis Fernando. Estados Unidos e América Latina: a construção da hegemonia. São Paulo: Unesp, 2002.

BETHELL, Leslie. A América Latina entre a Segunda Guerra Mundial e a Guerra Fria. Rio de Janeiro: Paz e Terra, 1996.

BEZERRA, Gustavo Henrique Marques. Brasil-Cuba: relações político-diplomáticas no contexto da Guerra Fria (1959-1986). Brasília: FUNAG, 2010.

BOBBIO, Norberto; MATTEUCCI, Nicola; PASQUINO, Gianfranco. Dicionário de política. Vol. 2. Brasília: UnB, 2010.

CERVO, Amado Luiz; BUENO, Clodoaldo. História da política exterior do Brasil. Brasília: UnB, 2015.

FAUSTO, Boris. História do Brasil. São Paulo: USP, 2002.

FERREIRA, Jorge Luiz; DELGADO, Lucilia de Almeida Neves (Coord). O Brasil Republicano. Rio de Janeiro: Civilização Brasileira, 2007.4 v.

GADDIS, John Lewis. We now know: rethinking cold history. Oxford: Clarendon Press, Oxford University Press, 1998.

HOBSBAWM, Eric. Era dos Extremos: o breve século XX: 1914-1991. São Paulo: Companhia das Letras, 1995.

IANNI, Octávio. Diplomacia e imperialismo na América Latina. São Paulo: CEBRAP, Caderno 12, 1973.

KARNAL, Leandro. História dos Estados Unidos: das origens ao século XX. São Paulo: Contexto, 2016. 
LOPES, Adriana. MOTA, Carlos Guilherme. História do Brasil: uma interpretação. São Paulo: Editora Senac São Paulo, 2008.

MENDONÇA, Sônia Regina de. As Bases do Desenvolvimento Capitalista Dependente: da industrialização restringida à internacionalização. In: LINHARES, Maria Yedda (org.). História Geral do Brasil. Rio de Janeiro, 1990.

MILLS, C. Wright. A verdade sobre Cuba. Rio de Janeiro: Zahar, 1961.

MONIZ BANDEIRA, Luiz Alberto. De Martí a Fidel: a Revolução Cubana e a América Latina. Rio de Janeiro: Civilização Brasileira, 2009. Luiz Alberto. Brasil-Estados Unidos: a rivalidade emergente (1950-1988). Rio de Janeiro: Civilização Brasileira, 2011.

Luiz Alberto. Presença dos Estados Unidos no Brasil. Rio de Janeiro: Civilização Brasileira, 2007.

NETO, Sydenham Lourenço. A Conferência do Rio de Janeiro e o Tratado Interamericano de Assistência Recíproca: conflitos na construção do sistema interamericano. Passagens: Revista Internacional de História Política e Cultura Jurídica, 2015. Acesso em: 17 de jun. 2017. $\mathrm{N}^{\circ}$ 3, p. 473-489. Disponível em: http://www.historia.uff.br/revistapassagens/inicio.php.

ODÁLIA, Nilo. O Brasil nas relações internacionais: 1945-1964. In: MOTA, Carlos Guilherme (org.). Brasil em perspectiva. Rio de Janeiro: Bertrand Brasil, 1995.

QUINTANEIRO, Tania. Cuba e Brasil: da revolução ao golpe (1959-1964). Belo Horizonte: UFMG, 1988.

SADER, Emir. A Revolução Cubana. São Paulo: Editora Moderna, 1985.

SANTOS, Luís Cláudio Villafañe G. A América do Sul no discurso diplomático brasileiro. Brasília: FUNAG, 2014.

SKIDMORE, Thomas E. Brasil: de Getúlio a Castello. São Paulo: Companhia das Letras, 2010. , Thomas E. Uma História do Brasil. São Paulo: Paz e Terra, 1998.

SWEEZY, Paul \& HUBERMAN, Leo. Cuba, anatomia de uma revolução. Rio de Janeiro: Zahar, 1961.

TOTA, Antonio Pedro. Os americanos. São Paulo: Contexto, 2013.

VAIL, John J. Fidel Castro. São Paulo: Nova Cultura, 1987.

VIZENTINI, Paulo G. Fagundes. Da barganha nacionalista à política externa independente, 1951-1964; relações internacionais e desenvolvimento no Brasil. In: CERVO, Amado Luiz. DÖPCKE, Wolfgang (org.). Relações Internacionais dos Países Americanos. Brasília: Linha Gráfica Editora, 1994.

WIGHT, Martin. A Política do poder. Brasília: UnB, 2002.

YOUNG, Jordan M. Brasil 1954/1964: fim de um ciclo civil. Rio de Janeiro: Nova Fronteira, 1973. 
ANEXOS 


\section{Anexo A}

Table 1

Cuba: Foreign Trade Overview ${ }^{56}$

Million US \$

\begin{tabular}{|c|c|c|c|c|c|c|c|c|c|c|}
\hline & 1958 & 1961 & 1963 & 1965 & 1967 & 1969 & 1971 & 1972 & $1973^{1}$ & $1974^{1}$ \\
\hline $\begin{array}{l}\text { Total exports } \\
\text { (f.o.b) }\end{array}$ & 742 & 626 & 545 & 691 & 705 & 671 & 860 & 837 & 1,380 & 2,745 \\
\hline Communist countries & 18 & 460 & 365 & 529 & 568 & 446 & 555 & 446 & 880 & 1,485 \\
\hline USSR & 14 & 304 & 164 & 323 & 366 & 233 & 304 & 244 & 565 & 935 \\
\hline Eastern Europe & Negl. & 63 & 125 & 103 & 113 & 130 & 160 & 137 & 210 & 375 \\
\hline Far East & 4 & 93 & 76 & 103 & 89 & 83 & 91 & 65 & 105 & 175 \\
\hline $\begin{array}{l}\text { Non-Communist } \\
\text { countries }\end{array}$ & 724 & 166 & 180 & 162 & 137 & 225 & 305 & 391 & 500 & 1,260 \\
\hline $\begin{array}{l}\text { Total imports } \\
\text { (c.i.f) }\end{array}$ & 860 & 707 & 832 & 866 & 999 & 1,222 & 1,387 & 1,297 & 1,700 & 2,450 \\
\hline Communist countries & 2 & 498 & 697 & 649 & 784 & 902 & 669 & 996 & 1,225 & 1,600 \\
\hline USSR & Negl. & 294 & 461 & 428 & 582 & 669 & 731 & 778 & 950 & 1,175 \\
\hline Eastern Europe & 2 & 104 & 145 & 98 & 119 & 139 & 143 & 126 & 150 & 225 \\
\hline Far East & Negl. & 100 & 91 & 123 & 83 & 94 & 95 & 92 & 125 & 200 \\
\hline $\begin{array}{l}\text { Non-Communist } \\
\text { countries }\end{array}$ & 858 & 209 & 135 & 217 & 215 & 320 & 418 & 301 & 475 & 850 \\
\hline
\end{tabular}

1. Provisional.

\footnotetext{
56 Cuba: Foreign Trade Overview. Disponível em:
} https://babel.hathitrust.org/cgi/pt?id=txu.059173026483710; view=1up;seq=13. Acesso: 27 jun. 2017. 